\title{
Editorial
}

\section{0th Conference of the German Society for Clinical Microcirculation and Hemorheology}

\author{
J.-H. Küpper ${ }^{\mathrm{a}}$, A. Krüger-Genge ${ }^{\mathrm{b}}$ and F. Jung ${ }^{\mathrm{a}, *}$ \\ ${ }^{a}$ Institute of Biotechnology, Molecular Cell Biology, Brandenburg University of Technology, \\ Senftenberg, Germany \\ ${ }^{\mathrm{b}}$ Department of Healthcare, Biomaterials and Cosmeceuticals, Division of Life Science and \\ Bioprocesses, Fraunhofer Institute for Applied Polymer Research (IAP), Potsdam-Golm, Germany
}

The 40th Conference of the German Society for Clinical Microcirculation and Hemorheology was held at Senftenberg, 5-6 November 2021. The conference was organized by Prof. Dr. Jan-Heiner Küpper from the Institute of Biotechnology, Brandenburgische Technische Universität CottbusSenftenberg, Senftenberg, Germany. Embedded in the conference of the DGKMH was the Conference of the German Society for Cellular Biotechnology - the sister society of the DGKMH. Both conferences were organized partly delocalized, with the speakers and attendees scattered across Germany, connected via a video-conferencing tool and social media. Some speakers from abroad (Canada, China, Hong Kong, Switzerland) also joined the Conference. Despite this delocalization, the meeting retained many characteristics of a traditional conference: invited and contributed talks with follow-up questions and discussion.

The congress was opened with a session about "Effects of microalgae ingredients on tissue and blood cells", one of the main topics of the group of the Conference President. The growth conditions and the use of microalgae in different fields is since more than 20 years in the focus of the Institute of Biotechnology at the BTU.

The conference counted with more than 80 participants mainly from Germany but also from other countries. A high-level scientific program was produced with excellent scientific presentations contributing to the increase of knowledge of basic and clinical microcirculation and hemorheology. The focus of the conference was traditionally oriented to the scientific interests of the society members, which are physiology and pathophysiology, pre-clinical and clinical studies, interactions of blood and tissue cells with body foreign materials, surgical and conservative therapy of lymph edema, cutaneous microangiopathy of severe vascular diseases as well as the diagnostic value of contrast-enhanced ultrasound.

\footnotetext{
${ }^{*}$ Corresponding author: F. Jung, Institute of Biotechnology, Molecular Cell Biology, Brandenburg University of Technology, Senftenberg, Germany. E-mail: friedrich.jung@b-TU.de.
} 
During fruitful discussions new questions arose and new opportunities of networking were initiated. Selected presentations of the Conference are published in this issue of Clinical Microcirculation and Hemorheology.

We wish to thank all participants and speakers for this fantastic conference. 